Para enlazar con este artículo / To link to this article:

http://dx.doi.org/10.14198/fem.2018.31.04

Para citar este artículo / To cite this article:

Estomba Giménez, Rosa María. "La expresión de la sexualidad en el mundo árabe: Túnez». En Feminismo/s, 31 (junio 2018): 83-106. Dosier monográfico: Sexo y bienestar. Mujeres y diversidad, coords. Carmen Mañas Viejo y Alicia Martínez Sanz, DOI: 10.14198/fem.2018.31.04

\title{
LA EXPRESIÓN DE LA SEXUALIDAD EN EL MUNDO ÁRABE: TÚNEZ
}

\section{THE EXPRESSION OF SEXUALITY IN THE ARAB WORLD: TUNISIA}

\author{
Rosa María ESTOMBA GIMÉNEZ \\ Universidad de Alicante \\ https://orcid.org/0000-0003-1147-5899
}

\section{Resumen}

A lo largo de este artículo pretendemos dar a conocer una visión general de la expresión de la sexualidad en Túnez, el tabú que supone y su relación con los cambios políticos que han tenido lugar en el país. Para ello, nos basamos en la marcada distinción entre el ámbito público y el privado en las sociedades árabes. Esta regula el comportamiento de sus habitantes, concebidos como una comunidad indivisible en la que la individualidad pasa a un segundo plano. Describiremos los fenómenos en los que se desarrolla la sexualidad de las personas y lo que ello supone para la inclusión de la diversidad sexual en las identidades árabes.

Palabras clave: sexualidad heteronormativa en el mundo árabe; sexualidad; género; homosexualidad.

\section{Abstract}

In this article, we're trying to raise awareness of the expression of sexuality (and its taboos) in a post-revolutionary Tunisia. We'll also see its connection with political changes that took place in the country. Our starting point is the strong distinction between public and private spaces in the Arab societies. That distinction rules the

Los contenidos de la revista se publican bajo una licencia de Creative Commons Reconocimiento 4.0 Internacional (CC BY 4.0)

Feminismo/s 31, junio 2018, pp. 83-106 
behaviour of their inhabitants, known as an indivisible community in which individuality is not that important. We will describe, in general, Tunisians' sexual context to understand how sexual diversity can be included in Arab identities.

Keywords: heteronormative sexuality in the Arab world; sexuality; gender; homosexuality.

\section{OBJETO DE ESTUDIO Y METODOLOGÍA}

Las conocidas como Primaveras Árabes han dado pie a que se traten temas en el debate público que anteriormente habían estado reservados a círculos académicos y alejados de la población. En el caso de Túnez, entre estas temáticas que han surgido tras la revolución y que todavía se tratan bajo un halo de discreción, cuando no suponen un tabú, encontramos la sexualidad. Esto, por supuesto, tiene que ver con la sociedad y la creación de una identidad propia. Nos apoyamos en la visión de El Feki cuando comenta:

Las actitudes y comportamientos sexuales están ligados a la religión, la tradición, la cultura, la política y la economía. Son parte de la sexualidad y todo lo que conlleva: roles de género e identidad, orientación sexual, placer, intimidad, erotismo y reproducción [...] la sexualidad es un espejo de las condiciones que llevaron a las revueltas y será una medida del progreso en las reformas de los años venideros. (18)

Los comportamientos sexuales de la población se manifiestan en diferentes fenómenos que trataremos a lo largo del artículo. Principalmente, en el matrimonio, que es la institución que regula las relaciones sexuales en sociedades de tradición islámica, considerándose toda relación sexual fuera de este como algo reprensible. No obstante, esto no impide a los habitantes vivir su sexualidad por otros medios, como veremos, generalmente a escondidas de los ojos de la comunidad cuya presión sobre el individuo es fuerte. Esto es algo que va de la mano con la esquizofrenia colectiva árabe de la que habla la libanesa Joumana Haddad: "[Los árabes] estamos divididos entre lo que se nos dice que debemos creer y lo que creemos, entre lo que decimos y lo que hacemos" (26). Así, trataremos aspectos generales sobre la manifestación de la sexualidad en Túnez tales como las relaciones prematrimoniales, la mitificación de 
la virginidad femenina, la situación del colectivo LGTBIQ, el fenómeno del acoso sexual y la prostitución.

A la hora de hablar de sexualidad en el mundo árabe, debemos tener en cuenta que el concepto (al-ŷinsìya), y todo lo relacionado con él, se considera tabú. Esto, por supuesto, no quiere decir que la sexualidad no se exprese o no se desarrolle en la región, sino que es un mundo restringido al ámbito de lo privado, especialmente en la expresión de la sexualidad femenina, lo que conduce en diversas ocasiones a cultivar un sentimiento de represión generalizado y una doble moral alimentada por las estructuras sociales patriarcales. Para el desarrollo de este artículo nos basaremos en autoras y autores conocidos por investigar en el ámbito de la sexualidad como el tunecino Abdelwahhab Bouhdiba con su estudio La sexualité en Islam que trata esta temática desde el punto de vista religioso, y la egipcia Shireen El-Feki con Sex and the cittadel, que reflexiona sobre la vida sexual en la región y su relación con los cambios sociales durante las conocidas como Primaveras Árabes. De igual manera, también nos apoyaremos en el trabajo de diferentes intelectuales tanto árabes como no árabes que tratan el tema, así como en artículos de prensa. Cabe decir que este artículo también se apoya en la observación y la experiencia personal de la autora en Túnez, lo cual ha dado pie en algunas ocasiones a realizar entrevistas y documentarse sobre el terreno.

Así, la metodología empleada para este artículo es heterogénea. Principalmente, se basa en el análisis de bibliografía específica sobre la sexualidad en el mundo árabe-islámico, ya mencionada. Desglosamos la información que ofrecen ensayos como el de El Feki, Bouhdiba... entre otros; así como la de artículos periodísticos de actualidad publicados por medios internacionales. Asimismo, pese a no profundizar en este aspecto dado que dotaría al artículo de un carácter especializado, no podemos obviar el papel de la lengua en este contexto. En este sentido, los trabajos de Badran y Olfa Youssef, además de la observación personal (inmersión lingüística en Túnez) nos proporcionan argumentos suficientes sobre el comportamiento de los hablantes respecto a estas cuestiones, por ejemplo, en los eufemismos utilizados para hablar de la sexualidad. No podemos obviar que la lengua es la expresión de la manera de ver el mundo por parte de los hablantes. Igualmente, ligadas a la observación sobre el terreno, hemos realizado entrevistas a ciudadanos tunecinos, como a la ginecóloga Rim Hachicha Kdous o a Youcef Bouzouida,

Feminismo/s 31, junio 2018, pp. 83-106 
trabajador de Abogados Sin Fronteras, que nos aportaron información en relación con la virginidad femenina. Por último, cabe añadir que también hemos basado la investigación en otros documentos que nos sirven como testimonio de la expresión de la sexualidad, ya no sólo en relación con la vida privada, sino con la ruptura de los tabúes sexuales en la sociedad. Estos son las producciones culturales que se están llevando a cabo en Túnez: novelas que tratan temática sexual y de género, películas y documentales, canciones... que muestran la diversidad sexual oculta.

\section{MARCO TEÓRICO}

Previamente a este trabajo, autoras y autores han estudiado la sexualidad y las relaciones de género en sociedades árabes. Muchos de ellos se han dedicado a estudiar la sexualidad dentro de los preceptos religiosos, es decir, el islam. Muchos de ellos han analizado minuciosamente los textos sagrados o tratados medievales, redactados por autoridades religiosas como alfaquíes, buscando argumentos que justifiquen o critiquen el comportamiento actual de estas sociedades en este ámbito.

Este punto de vista es interesante y aporta diversos argumentos de autoridad a la hora de "desmontar" mitos con respecto a la religión islámica. De hecho, autoras y autores como Bouhdiba, Chebbel u Olfa Youssef hacen un estudio profundo sobre cómo se conciben en el islam estas cuestiones desde un punto de vista objetivo. En los casos de Bouhdiba y Chebbel, presentan un análisis amplio y exhaustivo de las fuentes tradicionales y aportan información general sobre las sociedades árabes en el momento en el que redactan sus ensayos. Los ensayos de ambos autores nos ayudan a situar la expresión de la sexualidad en su contexto histórico y social. Olfa Youssef los interpreta basándose en sus conocimientos sobre lingüística e historia. Sus estudios nos ayudan a comprender el contexto conceptual en el que se desarrollan las relaciones sexuales: función reguladora del matrimonio, el zina, la homosexualidad... en este caso nos da pinceladas y presenta en rasgos generales cómo se comporta la sociedad tunecina, que es la suya. Sin embargo, no aportan datos concretos sobre el terreno que permitan un estudio profundo de la situación que actualmente se vive. Nos sitúan en un contexto teórico y nos ayudan a comprender la evolución de sociedades que se hayan desarrollado 
en el marco jurídico y religioso del islam, es decir, nos sirven de base para exponer los fenómenos que describiremos. Se trata de ejercicios de exégesis de los que se extrae abundante información pero que cuesta ver aplicada en el día a día precisamente por no ir acompañadas de un estudio con números y estadísticas.

No dudamos de que el conocimiento del contexto cultural y religioso en el que se desarrollan estas sociedades es fundamental, pero son necesarios estudios sobre el terreno en el que las voces de quienes conforman dichas sociedades den testimonio real, no únicamente sobre el papel, de las realidades que se viven a diario. Por eso una de las principales bases documentales y teóricas que han motivado la redacción de este artículo ha sido el ensayo de El Feki, que supone una triple ruptura de tabúes en sociedades árabes. La primera ruptura viene dada por tratar actualmente temas relativos a la sexualidad, un elemento que se ha envuelto en la opacidad en las últimas décadas a causa de factores como los procesos de colonización que han motivado la reivindicación de una identidad propia. Identidad que ha sido encontrada por diversos sectores en los movimientos integristas del islam, fuertemente reprimidos por los gobiernos posteriores a la colonización. A estos gobiernos se les ha acusado de continuar el esquema marcado por los países colonizadores (en el caso de Túnez, Francia), por lo que el recurso a una visión integrista de la religión surge como contraposición al otro, es decir, al colonizador y a los gobiernos continuadores de sus modelos. La segunda ruptura que lleva a cabo es su condición de género, al igual que Olfa Youssef, para tratar unas cuestiones que, además de suponer un tabú en la sociedad, el "desafío" es todavía mayor si es una mujer la que lo lleva a cabo. La tercera ruptura reside en el planteamiento de su ensayo. El Feki no se limita a describir los fenómenos relativos a la sexualidad en el mundo árabe, sino que entrevista una a una a las personas que son protagonistas de ellos en todo el mundo árabe y presenta sus vivencias para ejemplificar los apartados expuestos.

Asimismo, consideramos que no podemos pretender tratar la sexualidad sin hacerlo desde una perspectiva de género. Solamente de esta manera podremos comprender la naturaleza de los hechos expuestos. Para reflexionar sobre las condiciones que requiere el matrimonio, las restricciones en las libertades individuales (donde hallamos la libertad sexual), la invisibilidad de la sexualidad no heteronormativa, las brutales consecuencias de la prostitución,

Feminismo/s 31, junio 2018, pp. 83-106 
etc. es necesario tener en cuenta las relaciones de poder establecidas en las sociedades árabes por el sistema patriarcal (nid $\underline{d} \bar{m}$ abawī). Sistema que restringe las libertades de la mujer y limita sus roles en la sociedad situándola en condición de supeditación al género masculino.

\section{CONCEPCIÓN DE LA SEXUALIDAD EN EL MUNDO ÁRABE}

Para comenzar, conviene aclarar que si bien cada uno de los países que conforman la que conocemos como Liga Árabe tiene sus propias particularidades, comparten buena parte de características en lo que se refiere a sexualidad. Prácticamente, todo lo relativo al sexo (al-ŷins) es tabú en las sociedades árabes, especialmente en ambientes mixtos, además de estar reducido al ámbito conyugal. El matrimonio en el islam, como veremos más adelante, sirve como herramienta para regular las relaciones sexuales entre hombres y mujeres, mientras que toda relación extramatrimonial es considerada zina $\bar{a}$, es decir, adulterio (Bouhdiba 24).

El tabú que supone todo lo relativo al sexo se refleja de manera muy clara en el uso de la lengua, ya que se evita mencionar el término ŷins, idea que desarrolla Margot Badran (316) cuando analiza las pautas seguidas por los académicos para integrar en la lengua árabe el concepto de "género", en tanto que construcción social de lo masculino y lo femenino. Una de las propuestas terminológicas fue al-ŷins al-î́timāi Sin embargo, este término despertaba el pudor de los hablantes, sobre todo si se encontraban en un espacio mixto, al contener la palabra "sexo".

Todo lo relativo a la sexualidad se considera 'ayb wa harām, es decir, vergonzoso y prohibido, algo de lo que no se habla, que permanece escondido, reducido no solamente al ámbito de lo privado, sino de lo oculto. En este sentido, la escritora Joumana Haddad, al igual que otras escritoras árabes como Salwa Al-Neimi, reivindican la tradición erótica en la literatura árabe para nombrar con palabras fáciles y juguetonas lo que el árabe escrito lleva siglos callando (Sánchez Mediavilla).

Para recuperar dichas palabras, es necesario revalorizar la literatura árabe medieval por la naturalidad con la que se trata elementos relativos a la función sexual. Existen tratados medievales árabes redactados por alfaquíes (expertos en la jurisprudencia islámica) como Al-Nafzawi que, en el siglo XVI, redactó 
El jardín perfumado, un manual de erotología que desarrolla al detalle cuestiones relacionadas con el ámbito de la sexualidad: desde consejos para el uso de productos afrodisíacos hasta la descripción de métodos naturales de contracepción, pasando por descripciones minuciosas de los órganos sexuales femeninos y masculinos. Así, el hermetismo en el que se encuentran sumidas las sociedades árabes actuales contrasta con los testimonios de otras épocas que dan cuenta de la naturalidad con la que se hablaba de estos temas por parte de autoridades jurídico-religiosas como Al-Nafzawi o Al-Tifasi en Esparcimiento de corazones. Son tratados cuyo contenido choca con la realidad actual en la que la sexualidad se esconde y se reduce al ámbito del matrimonio, algo que está estrechamente vinculado al comportamiento social y a las estructuras de poder entre todos los actores que conforman la sociedad. Estructuras de poder que, como veremos, afectan al individuo en función de su clase social, su sexo o su orientación sexual, entre otras. Asimismo, la manera de tratar estas cuestiones refleja una "deuda" para con la moral pública (Chebel 22), la religión y la familia que da como resultado una hipocresía o doble moral que sale a relucir en fenómenos como la prostitución, prácticas sexuales que eviten la penetración vaginal, matrimonios secretos, la vida oculta de parejas homosexuales, etc. Cabe mencionar que cuando la sexualidad es tabú, quienes más sufren sus consecuencias son las mujeres y las minorías sexuales, es decir, los grupos más vulnerables (El Tahawy). En esta línea, veremos los ámbitos en los que la expresión sexual árabe tiene lugar, empezando por la institución del matrimonio, a partir de la cual desarrollaremos otros puntos que dan cuenta del comportamiento sexual que tiene lugar en la región árabe: parejas no casadas, parejas homosexuales, prostitución, virginidad femenina, colectivo LGTBIQ y el acoso sexual.

Investigadores como Shereen El Feki o Abdelwahab Bouhdiba señalan los factores que explican el hermetismo de las sociedades árabes contemporáneas en este ámbito. Son, principalmente, dos y tienen que ver con los procesos de colonización y con el auge de corrientes salafistas y wahabíes del islam que abogan por una visión ultraconservadora de este, relegando todo lo relacionado con la sexualidad a la finalidad meramente reproductiva. Esta, aunque intrínseca a la idea del matrimonio, no es la única finalidad de las relaciones sexuales ya que en el islam estas se entienden también como fin en sí mismas, recomendando, incluso, el uso de anticonceptivos. 


\section{MATRIMONIO}

Comenzamos hablando del matrimonio porque es la institución que regula las relaciones sexuales, no sólo con fin reproductivo, en sociedades de tradición islámica. En este sentido, poner atención en la etimología del término puede ayudarnos a comprender por qué se entiende como tal el matrimonio. A diferencia de lenguas romance en las que el origen del término matrimonio tiene que ver con la finalidad reproductiva de este, es decir, con ser madre (mater), en árabe el término "matrimonio", zawāŷ, indica dualidad, pareja. Hecho este apunte, podemos decir que las aspiraciones personales del individuo han de pasar por el matrimonio, entre otras cosas, porque los códigos penales de estos países, basándose en la jurisprudencia islámica, contemplan las relaciones sexuales fuera del matrimonio como delito. Esto se traduce en las restricciones para compartir piso entre personas de distinto sexo que no estén emparentadas o a la imposibilidad de reservar una habitación de hotel para parejas no casadas. De la misma manera, la presión que ejerce la sociedad sobre los individuos para que contraigan matrimonio es fuerte. Todo joven se siente en la obligación de encontrar una pareja con la que casarse. En el caso de las mujeres esto se acentúa, ya que el éxito de una mujer se sigue viendo ligado, aunque cada vez menos según el país, a su estatuto como esposa y madre (El Feki 36). Además, la finalidad reproductora del matrimonio en ocasiones supone falta de preocupación por que la mujer obtenga placer durante las relaciones sexuales como indican los testimonios de mujeres confiados a la doctora Kotb y recogidos en el amplísimo ensayo de El Feki (52).

En las últimas décadas, se ha retrasado la edad a la que se contrae matrimonio en las sociedades árabes, algo que poco a poco va cambiando las estructuras sociales. Son varios los factores que influyen en esto, entre ellos el acceso de la mujer a diversos niveles de estudios y a trabajos que anteriormente habían estado reservados a los hombres, además del deseo de progresar profesionalmente. De la misma manera, la situación económica de estos países, con altas tasas de paro juvenil, no propician la celebración de bodas que suponen altos costes, por lo que los jóvenes siguen dependiendo de la unidad familiar. 


\section{ZINĀ O VIDA SEXUAL FUERA DEL MATRIMONIO}

Retomando el concepto de adulterio en árabe, que hace referencia a todas las relaciones sexuales fuera del matrimonio, es interesante destacar la visión que nos da la doctora en lingüística Olfa Youssef en sus vídeos de YouTube, donde explica brevemente cuestiones sobre el islam. Este es un término presente en las fuentes islámicas, que como hemos mencionado sirven de base para la legislación de estos países. Como otras intelectuales e investigadoras, analiza pasajes del Corán y de los hadices ${ }^{1}$ situándolos en su contexto histórico. Remarca la necesidad de redefinir el concepto y abstraer de él matices que pueden resultar anacrónicos o incompatibles con la naturaleza humana y el instinto sexual, al reservar toda relación sexual para el matrimonio. Cabe explicar que, cuando nace el islam, la sexualidad podía manifestarse en otros ámbitos fuera del matrimonio, como por ejemplo la esclavitud. Además, argumenta que entonces el matrimonio se contraía a una edad mucho más temprana. Se trata de recursos que no son viables hoy día en el país norteafricano: ni el recurso a la esclavitud, ni el matrimonio a edades tempranas. Por eso actualmente no se puede pretender aplicar el uso clásico del término, pues no se ajusta a la realidad. No obstante, los individuos buscan las vías de escape necesarias para evitar el adulterio o zinā. Una de ellas es la prostitución en los países en los que esta está permitida; otra, mediante matrimonios que difieren de los oficiales, lo cual no quiere decir que no haya jóvenes parejas que mantengan relaciones sin recurrir a estos medios.

\section{Matrimonio 'urfī}

En el islam, el matrimonio, aparte de tener una finalidad reproductiva, regula la vida sexual de los creyentes porque las relaciones sexuales se consideran lícitas únicamente a partir del enlace conyugal. Así, con la excusa de evitar un matrimonio tradicional que implique un fuerte compromiso y de alejarse del adulterio entendido como toda relación sexual fuera del matrimonio, la jurisprudencia islámica contempla otro tipo de enlace. Encontramos el conocido como mut'a en el islam chií y el matrimonio 'urfī en el islam suní. El primero se conoce también como "matrimonio temporal" y tiene lugar, sobre

1. Recopilaciones de dichos y acciones que se le atribuyen al profeta Mahoma.

Feminismo/s 31, junio 2018, pp. 83-106 
todo, en Irán. El segundo es el que más nos interesa por ser propio del islam suní y el más practicado en países árabes del Norte de África, como Túnez.

En Túnez, este tipo de matrimonio no está reconocido por el Estado, así que no se ofrece ningún tipo de garantía a la pareja, especialmente a la mujer, en caso de divorcio o de embarazo. Como suele ocurrir con algunos artículos del código penal destinados a estas cuestiones, la celebración del matrimonio urfī está castigada por la ley, pero esta no suele aplicarse y queda únicamente sobre el papel. La unión solamente tiene validez espiritual, aunque muchos creyentes no consideran que el matrimonio 'urfī esté dentro del marco de la religión (El Feki 45). Sin embargo, a otros que sí lo consideran como tal les sirve como excusa para practicar su sexualidad sin que esto contradiga sus preceptos morales y religiosos, ya que quienes lo llevan a cabo no lo consideran adulterio. Quienes más recurren a él en el país norteafricano son jóvenes estudiantes islamistas. El matrimonio urfī puede realizarse en secreto, ya que únicamente se necesita la presencia de dos testigos, que suelen ser amigos íntimos de los futuros cónyuges o autoridades religiosas locales (Baldé). Esto dificulta todavía más las cosas a la hora de asumir responsabilidades.

El adulterio, dentro del contexto de las relaciones prematrimoniales, está estrechamente vinculado a la virginidad. Puesto que el matrimonio es el punto de partida para tener relaciones sexuales, la virginidad, sobre todo la femenina, es un requisito a la hora de contraer el primer matrimonio.

\section{VIRGINIDAD FEMENINA}

La virginidad femenina está íntimamente ligada al concepto de "honor" (ร̌arf) que hoy día continúa vigente. Especialmente en zonas rurales y zonas urbanas pobres. Tras conversar con trabajadores de Abogados Sin Fronteras en Túnez, nos hicieron saber que existen diversas expresiones para referirse a una chica virgen: "una chica con honor", "una chica limpia" o "una chica que no está rota". También existen rituales que tienen lugar en la noche de bodas para corroborar ante los invitados que la novia no ha mantenido relaciones sexuales antes de casarse. Boukhayatia presenta varios testimonios en su artículo sobre la virginidad en Túnez. A modo de ejemplo, en algunas regiones, el novio coloca una vela encendida en la ventana si la novia ha sangrado después del coito. Cabe decir que en función del país y la región de la que

Feminismo/s 31, junio 2018, pp. 83-106 
hablemos, estos rituales varían y pueden ser más violentos, mostrando una sábana blanca con la sangre de la novia.

Todos estos elementos no dejan de ser una muestra del dominio patriarcal sobre el cuerpo de las mujeres. Normalmente, se suele señalar a la religión cuando se trata de estos asuntos y es cierto que el islam apela a la virginidad femenina al mencionar a la Virgen María o a las huríes del paraíso. Sin embargo, como señala El Feki (112), algunas fuentes islámicas no aconsejan este tipo de ritual en las nupcias e incluso crean subterfugios que ofrecen argumentos a los creyentes para desarrollar su sexualidad, como es el caso del matrimonio 'urfī.

La virginidad femenina, entendida como un himen intacto, se convierte en un requisito social para el matrimonio (Chebel 85) y en una auténtica obsesión tanto para ellas como para sus familias. Esta obsesión se refleja en la vida cotidiana. Valga como ejemplo las dificultades con las que se tropieza una mujer en busca de tampones, ya que la mayoría de los sectores de la sociedad consideran que pueden romper su himen y convertirla en una "chica rota". En el caso del hombre es un hecho normalizado que el novio haya tenido alguna experiencia previa (Chebel 45), lo cual no le exime de desear una esposa virgen.

La presión a la que se ven sometidas las jóvenes tunecinas, y árabes en general, las lleva a tomar medidas en caso de que hayan mantenido relaciones prematrimoniales. Como indica Haddad, "la vida y las historias propias [en una sociedad árabe] hay que reescribirlas para complacer a las vestales de la castidad árabe, para que tengan la certeza de que el delicado "himen" árabe está a salvo" (21). La ginecóloga Rim Hachicha Kdous, nos hizo saber, en la entrevista que tuvimos con ella, que un gran porcentaje de mujeres que tienen una boda por delante recurren a la himenoplastia para llegar "vírgenes" a la noche de bodas.

\section{COLECTIVO LGTBIQ}

En este punto es imprescindible prestar atención en la terminología empleada para referirse a los individuos que integran este colectivo, haciendo hincapié en las palabras empleadas para referirse a la homosexualidad, presentes en el árabe clásico. La homosexualidad masculina se conoce como liwät, 
sodomía, y la femenina como musāhaqa, lesbianismo. Las etimologías de ambas palabras son interesantes porque hacen referencia exclusivamente a las prácticas sexuales. Por un lado, liwāt tiene que ver con el relato bíblico de Sodoma y Gomorra y hace referencia a Lot. En el relato, Dios calcina ambas ciudades por el comportamiento de sus hombres, quienes acostumbraban a mantener relaciones sexuales no consensuadas, es decir, violaciones, con otros hombres. Por otro lado, musāhaqa procede de una raíz que tiene que ver con "frotar". Además, tras nuestra propia experiencia en el seno de la sociedad tunecina y haber estado en contacto con la lengua empleada por los tunecinos, hemos documentado que, a la hora de referirse, sobre todo a los hombres homosexuales, existen varios términos despectivos que suelen equiparar la orientación sexual con el sexo y el género: "enculado" (mebūn), "no-hombre" (muš râ̂ul), etc.

Sin embargo, en los últimos años se ha extendido, especialmente entre la sociedad civil, otro término exento de connotaciones negativas o discriminatorias. Se trata del término mizli ŷinsī. Mizl responde a una raíz polisémica y entre sus significados, encontramos: semejante, imagen, equivalencia... para evitar confusiones, se le adjunta el adjetivo $\hat{y} i n s \bar{\imath}$, sexual, y de esta manera mizl equivale al prefijo griego homo-. Al igual que este, en las últimas décadas se han creado otros neologismos en árabe relacionados con la diversidad sexual y el colectivo LGTBIQ como bisexual, muzdāwi $\hat{y}$ al-yinsī; heterosexual, ghairī; o transexual, mutahawil (Semerene).

La homosexualidad está presente en el Código Penal de todos los países árabes y resulta curioso destacar que entró a formar parte de este durante los procesos de colonización. En el caso de Túnez, se trata del artículo 230:

“،اللو اط أو المساحقة إذا لم يكن داخلا في أي صورة من الصور المقرّرة بالفصول المتقدمّة بعاقب مرتكبه بالسجن مدة ثلاثة أعوام”

"La sodomía y el lesbianismo, si no entraran en ninguno de los casos previstos en los artículos precedentes, son castigados con tres años de cárcel."

Como señala Sbouai, el Código Penal tunecino fue promulgado en 1913, unos cuantos años antes de la Independencia (1956) y es aplicable si quienes llevan a cabo el acto son adultos, conscientes y lo realizan en el ámbito privado. Normalmente, el hecho de llevarse a cabo en el ámbito privado y necesitar testigos hace que estas medidas no se apliquen de manera sistemática. Al 
tratarse de un artículo promulgado durante la época colonial, vemos necesaria una mención a la tradición homoerótica árabe.

En los tratados medievales que ya hemos mencionado se registran relatos y poemas homoeróticos que son testimonio de la naturalidad con la que se trataban las relaciones homosexuales. Aunque estos relatos den cuenta de una mentalidad más abierta en cuanto a la homosexualidad que, por ejemplo, las sociedades cristianas de la época, no debemos caer en mitificaciones de ese pasado. Según refleja el uso del término lūṭi, las relaciones entre personas del mismo sexo aparecen reducidas exclusivamente al ámbito sexual, sin considerar relaciones afectivas entre ellas, como señala Gutiérrez de Terán en el prólogo de El jardín perfumado (Al Nafzawi 37). Estas representaciones suelen aparecer en tono de burla y ensalzando la figura del activo, al estar en el papel dominante, frente a la humillación del pasivo, que es a quien se califica de afeminado o mu'annaz. Así y todo, no podemos negar lo que este legado denota y esto es una visión normalizada de las relaciones entre personas del mismo sexo dentro de la región árabe, algo que no ocurre hoy día.

Prueba de ello es la ilegalidad de sus prácticas sexuales y las discriminaciones a las que están expuestas estas personas en el seno de la sociedad. Estas ideas en torno a las relaciones homosexuales responden, según El Feki, a dos aspectos (239). Por un lado, a los procesos de colonización porque estos se llevaron a cabo desde un punto de vista cristiano en el que la sexualidad siempre ha sido más que un tabú y ha estado relegada a la finalidad reproductiva. En este sentido, no es de extrañar que la promulgación de leyes contra las relaciones homosexuales coincida con estos períodos. Por otro lado, también muy importante, tenemos el auge del wahabismo, una corriente del islam nacida en Arabia Saudí que exporta una visión extremadamente conservadora de la religión. Abogan por volver a lo que consideran los orígenes del islam, aunque diversas interpretaciones de los textos sagrados se contradicen entre sí. Por ejemplo, la citada investigadora tunecina Olfa Youssef, especialista en lingüística árabe y en los textos sagrados del islam, indica en su vídeo dedicado a la homosexualidad en el islam (Al-mitliyat al-ŷinsiya maskut 'anha fì-l-islām) que la homosexualidad no está prohibida ya que la única mención que se hace a esta es en el relato de Lot y lo que se condena es la actitud de los habitantes de Sodoma y Gomorra para con los invitados, no las relaciones sexuales entre personas del mismo sexo. Igualmente, la investigadora señala

Feminismo/s 31, junio 2018, pp. 83-106 
que en cuanto a la homosexualidad femenina (musāhaqa), esta ni siquiera se menciona en dichas fuentes.

Volviendo al caso concreto de Túnez, durante la colonización francesa y los posteriores regímenes autoritarios, la expresión de la sexualidad del colectivo LGTBIQ ha permanecido oculta, invisibilizada bajo la prerrogativa de "lo que no se nombra no existe". En este sentido, cabría comentar que la expresión sexual del colectivo (siempre bajo un halo de discreción y en el ámbito privado) fue tolerada por el régimen de Ben Ali. En cuanto a la influencia de corrientes islamistas conservadoras, destacan, especialmente, los momentos de tensión que se vivieron entre grupos políticos laicos y otros de corte islamista durante los primeros años de la transición democrática (2011-2012) en la que todavía hoy sigue sumido el país.

La homofobia es una de las lacras contra las que lucha la sociedad tunecina. El estigma social del colectivo LGTBIQ es un hecho patente, sobre todo en los últimos años. Tras la conocida como Revolución del Jazmín (2011), los tunecinos han ganado en libertad de expresión. Así, fenómenos que antes se silenciaban están teniendo mayor visibilidad. En el caso de la homosexualidad, se va avanzando poco a poco y hoy día, Túnez cuenta con la primera emisora en el mundo árabe que trata cuestiones relacionadas con el colectivo.

Resulta interesante añadir en este apartado las agresiones a las que están expuestas personas que son identificadas con el colectivo LGTBIQ. Cabe destacar cómo afecta la jerarquía social a esta comunidad, ya que hay "niveles" de tolerancia que, al fin y al cabo, responden a la discriminación de clase (Aiachi). Esto es algo que se refleja en las relaciones sociales y en la aceptación de la diversidad sexual. Cuando hablamos de que tras la revolución se le ha dado mayor visibilidad a este colectivo, hablamos de grandes ciudades costeras o situadas en el norte del país frente a otras ubicadas en el sur o en el interior, donde la discriminación sigue siendo intensa. En todo caso, la discriminación hacia este colectivo es algo habitual en diversos aspectos de la vida cotidiana: prejuicios, chistes, burlas, agresiones, abusos de las fuerzas del orden... como denuncia la asociación Shams en el documental Au pays de la démocratie naissante, producido en 2017.

Asociaciones como Shams o Damj en Túnez se movilizan y luchan por avanzar en el terreno de los Derechos Humanos y abolir el ya citado artículo 230 del Código Penal tunecino. Si bien es cierto, como hemos dicho, que este

Feminismo/s 31, junio 2018, pp. 83-106 
no se suele aplicar porque precisa de testigos, no quiere decir que quienes se identifican con este colectivo no estén expuestos a agresiones tanto verbales como físicas. En este sentido, es interesante destacar que, hasta hace menos de un año (González, "Shams rad, la primera radio gay del mundo árabe"), la sospecha de homosexualidad llevaba a muchos chicos a ser sometidos a tests anales en contra de su voluntad, algo que fue denunciado como tortura por diversas organizaciones. La situación es especialmente crítica con la homosexualidad masculina. La femenina, en cambio, es "visiblemente invisible" de manera que la opinión pública no las tiene en cuenta.

Las mujeres lesbianas se hallan bajo una opresión mayor incluso en comparación con los hombres homosexuales, ya que estos tienen mayor libertad y su situación es expuesta en el debate público. Así, las mujeres lesbianas en Túnez están sometidas a un doble estigma: ser mujer y lesbiana en una sociedad que restringe sus libertades. Son dos posiciones que las sitúan en un segundo plano y que limitan fuertemente la vida personal porque el aislamiento en el que se encuentran les imposibilita relacionarse con personas en la misma situación (El Feki 250).

\section{ACOSO SEXUAL}

Tras las conocidas como Primaveras Árabes uno de los temas que más ha dado que hablar ha sido el acoso sexual (taharruŷy yinsī) hacia las mujeres, algo extendido en toda la región árabe. En Túnez, las mujeres también estuvieron presentes en las protestas e incluso jugaron un papel protagonista, como la activista Lina Ben Mheni, que se convirtió en un símbolo de la revolución al publicar en su blog el seguimiento de las protestas y sus propias ideas. Esto es algo que no era posible hacer en los medios convencionales afines al régimen. La libertad de expresión conseguida tras la revolución contribuyó a que se pusiera en tela de juicio el feminismo de Estado ${ }^{2}$ llevado a cabo por

2. El presidente Bourguiba, el primero que tuvo Túnez tras conseguir la independencia de Francia, es conocido por modificar el Código del Estatuto Personal tunecino y promulgar leyes a favor de la mujer como la abolición de la poligamia, la desaparición de la figura del tutor legal de la mujer, la introducción del divorcio en el código penal, el derecho a la educación, etc. Ben Ali, su sucesor, continuó con la aplicación de estas medidas. Medidas que en diversas ocasiones han sido consideradas como exportación de una imagen abierta hacia Europa. Esto se debe a la existencia de una brecha entre

Feminismo/s 31, junio 2018, pp. 83-106 
los gobiernos de Bourguiba y Ben Ali y del que también se ha acusado al gobierno actual (Ghribi).

El acoso sexual en las calles de sociedades árabes es un hecho bastante corriente y constituye uno de los aspectos más visibles en relación con la violencia contra las mujeres. En comparación con otros países árabes como Egipto (Abdelmonem 96), Túnez presenta una sociedad en la que la cohabitación de ambos sexos en un mismo espacio está más normalizada debido, en parte, a su status de "excepción árabe" en cuanto a cuestiones de género. Así y todo, siguen existiendo tradiciones, como las relativas a la virginidad femenina, y comportamientos profundamente misóginos que regulan o marcan la vida de las mujeres en el espacio público ${ }^{3}$. El acoso sexual es uno de ellos.

Conviene señalar aquí la importancia que se le da a la vestimenta de las mujeres en el espacio público y la relación con una posible agresión sexual. Normalmente, cuanto más se cubre una mujer, menos expuesta se siente. No es difícil entender por qué si atendemos al concepto de 'awra, en sociedades de tradición islámica. Dicho concepto se refiere a lo que debe ser protegido y esto, en relación con el cuerpo, son las partes íntimas tanto del hombre como de la mujer. El 'awra es diferente en cada uno de los sexos, correspondiendo el de la mujer con todo el cuerpo salvo las manos y la cara (Lapiedra 107).

Otro concepto fundamental en las sociedades de tradición islámica es el de tabarruy, tratado por Manuela Marín y que hace referencia a las mujeres que muestran sus adornos en público ante hombres con los que no tienen ningún parentesco. En las fuentes islámicas se indica que estos adornos son exhibidos mediante prendas o accesorios que potencian el atractivo de la mujer, así como mediante una actitud licenciosa por parte de esta. Actitud licenciosa que no siempre se mide con la misma vara y que la amplitud semántica del término tabarruŷ permite realizar juicios distintos al respecto. Así, donde unos acusan de tabarruŷ a mujeres sin velo que coquetean abiertamente con hombres, otros lo hacen al verlas pasear por la calle con los cuerpos cubiertos (227). En todo caso, el denominador común es la expresión

las leyes y la aceptación social de estas, especialmente en zonas rurales y en barrios humildes.

3. Entendemos como espacio público, también, la actividad en redes sociales como Facebook (Bouzid 48)

Feminismo/s 31, junio 2018, pp. 83-106 
de la identidad femenina en el espacio público, juzgada por los varones de la familia con el fin de preservar su honor, es decir, el acceso a sus mujeres.

Así, no es de extrañar que, como ocurre en toda sociedad fundada bajo el patriarcado, se muestre una preocupación por la ropa que lleva la mujer y su estilo de vida a la hora de relacionarlos con una posible violación. Esto a menudo se traduce en que la culpa y la responsabilidad de las agresiones sexuales sufridas por mujeres recaigan sobre las mismas.

El acoso sexual en las calles, transporte público, etc... es un hecho normalizado en la sociedad tunecina que se refleja en la escasa presencia de mujeres en espacios públicos como cafés y bares, a excepción de zonas turísticas o elitistas (Bessis 38). En 2016, el gobierno tunecino promulgó una ley que castiga este tipo de comportamientos de acoso si son denunciados. Sin embargo, la sociedad civil califica esta medida de insuficiente e inútil si no va de la mano con campañas de sensibilización a la sociedad.

\section{PROSTITUCIÓN}

La prostitución en el mundo árabe constituye el aspecto más evidente y también el más escondido de la sexualidad árabe. Ya se desarrolle de manera clandestina o sea regulada por el Estado, supone un reflejo del poder patriarcal porque, principalmente, quienes padecen las consecuencias negativas de esta son las mujeres, ya que se ven supeditadas al poder del hombre (bien clientes; bien proxenetas) en una actividad que las despoja de humanidad al no ser consideradas personas (Beauvoir 656), además de los problemas de salud física y psicosociales a los que están expuestas, por ejemplo: Enfermedades de Transmisión Sexual (ETS), embarazos no deseados, violaciones, trastornos psicológicos, problemas en las relaciones sociales...

No en todos los países árabes se halla regulada la prostitución, lo cual no quiere decir que no se lleve a cabo. Como indica la investigación de El Feki (192), encontramos diversos perfiles de cliente. Por un lado, los autóctonos que recurren a estos servicios suelen hacerlo debido a que sus mujeres carecen de experiencia, para realizar prácticas que dentro del matrimonio se les niegan porque las consideran harām o despiertan su pudor (sexo anal y oral, principalmente) o porque están solteros y desean tener experiencias sexuales. Por otro lado, la región árabe es testigo de lo que conocemos como turismo

Feminismo/s 31, junio 2018, pp. 83-106 
sexual en el cual podemos encontrar tanto clientes de países árabes vecinos como occidentales. Sin embargo, supone un gran tabú en la sociedad que pocos se atreven a sacar a la palestra.

Las mujeres que ofrecen estos servicios son con frecuencia chicas jóvenes que posteriormente encuentran muchas dificultades para salir del mundo de la prostitución. A esto se suma el desconocimiento de los recursos sociales para la reinserción, en los países que cuentan con estos, y la falta de educación sexual en las escuelas, lo que las expone a diversos riesgos: ETS, SIDA y embarazos no deseados, además de la estigmatización social. Otro perfil común es el de mujeres divorciadas y, en general, con escasos recursos económicos, que no encuentran otra opción igual de remunerada para mantener a sus familias.

En Túnez, la prostitución es legal siempre que se trate de algo público, es decir, algo que esté regulado por el Estado. De lo contrario, el código penal del país (artículos 231 y 232) castiga tanto a la prostituta como al cliente con penas de entre seis meses de cárcel hasta los dos años, si esta es ejercida de manera clandestina. Es el Ministerio del Interior el que se encarga de certificar que las condiciones en el burdel son las adecuadas para prestar el servicio. Una de las medidas para lograr esto son los reconocimientos médicos semanales a las mujeres registradas para ejercer en zonas de las que no pueden salir sin autorización policial. El enclave principal en la capital tunecina se halla en la medina, el casco antiguo (González, "Prostitución, la otra excepción tunecina").

La prostitución de mujeres, siguiendo las medidas mencionadas, es la única que está permitida por el gobierno de Túnez. No obstante, esta se lleva a cabo de manera clandestina y el cliente tiene mayor libertad para realizar las prácticas que le apetezcan, algo que sin duda da pie a que tengan lugar fuertes abusos, entre ellos la trata de seres humanos. No es fácil el acceso a información relacionada con la prostitución en el país. Ni siquiera para las ONG,S o para periodistas...Podemos acceder a artículos que recogen el testimonio de mujeres que ejercen la prostitución ilegal en el país y que, además, son víctimas de trata. No obstante, no se ha realizado un estudio profundo debido a la falta de colaboración de las autoridades tunecinas (Sbouai, "Esclave en Tunisie"). Según Sbouai, los testimonios sueltos de las víctimas de trata dan cuenta de una trama bien organizada en la que las redes de captación conocen las condiciones de los países involucrados. Pero la prostitución femenina no

Feminismo/s 31, junio 2018, pp. 83-106 
es la única forma de prostitución en Túnez. Existe una figura presente en zonas costeras llamada bezness que corresponde a hombres jóvenes que son pagados por mujeres europeas para gozar de idilios románticos durante las vacaciones (El Feki 196). Se trata de historias que crecen en un contexto alejado de las normas locales, especialmente en resorts turísticos. Por último, señalamos la prostitución de personas homosexuales, regulada por códigos sociales, centrados en la comunicación no verbal. Si la prostitución como concepto ya es un tabú, la prostitución de personas homosexuales lo es todavía más por la discriminación a la que están sometidas. Sin embargo, los cafés, bares y centros frecuentados por estos profesionales son bien conocidos por la sociedad. En resumen, la prostitución en todas sus formas, tanto en el plano lícito como en el ilícito, es un fenómeno que siempre ha existido en la sociedad tunecina, lo único que las diferencia, según Aiachi es, además de la recaudación de impuestos, el grado de discreción.

\section{CONCLUSIÓN}

Tras lo expuesto en el artículo, queda constancia de que la sexualidad en la sociedad tunecina, pese a ser un tema tabú porque no se habla de él, conforma, como en cualquier otra sociedad, un aspecto más de la vida de los individuos que la integran. Así, al tratarla como un asunto prohibido y vergonzoso que no tiene cabida en el debate público, se crea la situación perfecta para el desarrollo de fenómenos como los tratados: discriminaciones, abusos, invisibilidad en el seno de la sociedad, vidas ocultas, presiones a la hora de contraer matrimonio, falta de control sobre el propio cuerpo... Podemos afirmar que la consideración de la sexualidad como objeto tabú es un hecho extrapolable a otras sociedades árabes, ya que se trata de sociedades cuyos fenómenos sociales comparten características y, si bien los matices varían entre unas y otras, en rasgos generales se asemejan.

Igualmente, si profundizamos en el análisis de estos comportamientos, nos daremos cuenta de que hallan su base en el patriarcado, un sistema de organización social que también está presente en sociedades occidentales.

En Túnez se repiten patrones de las estructuras de poder que alimentan la doble moral e hipocresía predominantes en el panorama social árabe. Esta hipocresía se refleja en todos los puntos que hemos visto, varios de ellos 
interrelacionados. Uno de los más importantes es el relativo a la prostitución dadas las brutales consecuencias que puede conllevar para quienes la ejercen, además de para quienes son víctimas de trata. Sacar a la palestra las realidades que conciernen a la sexualidad hace que situaciones en las que se violan los derechos humanos se visibilicen y acaben tomándose medidas al respecto. Desgraciadamente, en el campo de la prostitución todavía hay un largo camino que recorrer, ya que los estudios que profundicen en ella son escasos, especialmente en lo concerniente a la trata.

Además de en la prostitución como fenómeno oculto son diversos los ámbitos en los que podemos observar la doble moral criticada por voces árabes. Por ejemplo, una fuerte diferenciación del ámbito público y privado que deriva en el establecimiento de unas normas en el espacio público que en el privado se pueden subvertir porque no está expuesto a ojos de los demás. En el ámbito del matrimonio, la doble moral se manifiesta en diversos elementos. Uno de ellos es la exigencia de que la novia permanezca virgen mientras el novio no es juzgado ni ve en detrimento su status social al haber mantenido relaciones prematrimoniales, sino todo lo contrario. En relación con el sexo prematrimonial, los matrimonios 'urfī son, para los creyentes, un claro ejemplo de las prácticas que nutren ese doble rasero, pues suponen una excusa para mantener la conciencia tranquila y disfrutar así de la propia sexualidad en el marco ético de la religión. De igual manera, las himenoplastias denotan esa dualidad entre lo público y lo privado. Lo que se busca mediante la operación es mantener un status social respetable ante la comunidad, lo cual está motivado por la presión social, pública, a la que están sometidas las mujeres. En la línea de la tesis de El Feki, con la que abríamos este artículo, nos hacemos la siguiente pregunta: ies el feminismo de Estado otra muestra de esa doble moral a la que hemos aludido a lo largo del artículo? El doble rasero lo vemos en un país de tradición islámica con leyes modernas y abiertas, especialmente en relación con los derechos de las mujeres. Se trata de algo que dota a Túnez, en comparación con los otros países de la región, del status innegable de "excepción árabe". Sin embargo, la intelectualidad tunecina considera que estas medidas, llevadas a cabo por los regímenes autoritarios de Bourguiba (1957-1987) y Ben Ali (1987-2011) fueron medidas "de maquillaje" que exportaban a Europa una imagen muy

Feminismo/s 31, junio 2018, pp. 83-106 
amable y positiva de las mujeres tunecinas pero que no se preocuparon de influir sustancialmente en la sociedad del país.

En relación con el cumplimiento o preservación de los derechos humanos, debemos dedicar unas líneas a tratar estos, concretamente los derechos sexuales. Estos no dejan de formar parte de los primeros, a nivel individual y social. En Túnez son varios los derechos sexuales que se ven vulnerados, comenzando por el derecho a la autonomía, integridad y seguridad sexuales del cuerpo en el campo de la prostitución, pero también en la obsesión por la virginidad femenina, que se traduce en comprobaciones durante la noche de bodas o himenoplastias por las que pasan muchas mujeres. El derecho a la equidad sexual tampoco se cumple debido a las constantes discriminaciones hacia el colectivo LGTBIQ. Asimismo, el derecho a la libre asociación sexual se ve coartado desde el momento en el que la única vía legal que se contempla para regular las relaciones sexuales, aparte de la prostitución, es el matrimonio heterosexual. Así, como señala Lilia Rodríguez (12), "la distancia entre los derechos fundamentales reconocidos y la práctica de ellos es grande". Aunque estos estén reconocidos por la Organización de las Naciones Unidas, no se cumplen universalmente. De hecho, se ven vulnerados en muchos puntos geográficos del mundo.

Actualmente, siete años después de la Revolución del Jazmín, el descontento social, principalmente por la situación económica, vuelve a extenderse por el país, de nuevo desde zonas del interior hacia las grandes capitales. Sin embargo, 2017 ha sido testigo de varios pequeños avances en el plano de la expresión de la sexualidad y la diversidad sexual en Túnez. Por ejemplo, aunque todavía no se ha despenalizado la homosexualidad, se ha conseguido que dejen de realizarse los tests anales a los que eran sometidos hombres de los que se sospechaba haber tenido sexo anal. La visibilidad del colectivo LGTBIQ en el país es mayor gracias al trabajo de asociaciones como Shams, una de las más combativas a este respecto y que recientemente ha creado una emisora de radio que trata temas de interés general desde la perspectiva del colectivo. Asimismo, ha habido diversas manifestaciones culturales en Túnez relativas a la sexualidad: el festival de arte feminista Chouftohonna (septiembre 2017), el espectáculo de literatura erótica Artgasme (diciembre 2017) y el festival de cine centrado en la realidad LGTBIQ Mawjoudin (enero 2018). 
Por último, cabe añadir que son muchas, a lo largo y ancho del mundo árabe, las manifestaciones culturales que visibilizan cuestiones relacionadas con la sexualidad. La relevancia de estas reside, aparte de en el proceso creativo, en el radio que tienen. La producción de literatura, películas o música que traten estas cuestiones es fundamental porque, en la mayoría de los casos, esto incide más en la sociedad que unas leyes sobre el papel y que el ciudadano olvida que existen si no se promueven campañas de concienciación. Ejemplos de ello son la novela El sabor de la miel de la siria Salwa Al-Neimi, El edificio Yacobián del egipcio Alaa Al-Aswani que tratan historias sobre el sexo en sociedades árabes; películas tunecinas como Cuando abro los ojos, dirigida por Leyla Bouzid, o Narcisse, Aziz Rouhou, dirigida por Sonia Chamkhi, etc. Existen representaciones de estos temas en todos los géneros artísticos árabes, pero son especialmente importantes las que se dan en el panorama musical puesto que se trata de un medio de expresión que llega a buena parte de los jóvenes árabes. Así, destacamos el grupo libanés Mashrou' Leila por ser un símbolo de la lucha LGTBIQ a lo largo de toda la región.

\section{REFERENCIAS BIBLIOGRÁFICAS}

Abdelmonem, Angie. "Reconsiderer la dépolitisation: l'approche du témoin de HarassMap et la création d'une masse critique pour lutter contre le harcèlement sexuel en Égypte". Égypte/Monde árabe, Nouvelles luttes autour du genre en Egypte depuis 2011. Ed. Leslie Piquemal, 2015. 93-113. http://journals.openedition.org/ ema/3532. 3 enero 2018.

Aiachi, Sophie Alexandra. "Homosexualité en Tunisie, et si on en parlait?". Nawaat, 2011. https://nawaat.org/portail/2011/12/02//homosexualite-en-tunisie-et-si-on-en-parlait/. 24 noviembre 2017.

Al-Nafzawi. El jardín perfumado. Traducción del árabe de Ignacio Gutiérrez de Terán y Naomí Rodríguez Díaz. Madrid: Ediciones del Oriente y del Mediterráneo, 2014. Al-Tifasi. Esparcimiento de corazones. Traducción del árabe: Ignacio Gutiérrez de Terán. Madrid: Gredos, 2003.

Badran, Margot. Feminismo en el islam. Traducción del francés: Tania Arias. Madrid: Cátedra, 2009.

Baldé, Assanatou. "Dalenda Larguèche: "Le mariage coutumier en Tunisie est une version halal de la liberté sexuelle des jeunes"”. Afrik, 2012. http://www.afrik. com/article24741.html. 5 diciembre 2017.

Feminismo/s 31, junio 2018, pp. 83-106 
Beauvoir, Simone. El segundo sexo. Traducción del francés: Alicia Martorell. Madrid: Cátedra, 2018.

Bessis, Sophie. Los árabes, las mujeres, la libertad. Traducción del francés: Florencia Peyrou Tubert. Madrid: Alianza Editorial, 2008.

Bouhdiba, Abdelwahab. La sexualité en Islam. París: Presses Universitaires de France, 2003.

Boukhayatia, Rihab. "La virginité en Tunisie, sacralisée... mais contournée". Huffpost Maghreb, 2016. http://www.huffpostmaghreb.com/2016/02/11/tunisie-virginite-contourne_n_9208114.html. 27 diciembre 2017.

—. "La virginité est-elle aussi importante pour l'homme tunisien? Pas si sûr, pas de la même manière?". Huffpost Magreb, 2016. http://www.huffpostmaghreb. com/2016/11/09/tunisien-virginite-femme-_n_12880002.html. 28 diciembre 2017.

-. "Tunisie - Une nuit dans un cabaret: 'Laisser faire, tout en gardant en tête la ligne rouge à ne pas dépasser". Huffpost Maghreb, 2015. http://www.huffpostmaghreb. com/2015/10/22/une-nuit-dans-un-cabaret-_n_8355756.html. 29 diciembre 2017.

Bouzid, Mouna. Facebook made in Tunisia. Túnez: Alyssa Edition et Diffusion, 2016.

Chaouch, Yasmine. "Prostitution des étudiantes. Voyage au coeur d'un tabou". Inkyfada (2015). https://inkyfada.com/2015/03/prostitution-etudiante-voyage-coeur-tabou-tunisie/. 29 diciembre 2017.

Chebel, Malek. El espiritu de serrallo. Estructuras y variaciones de la sexualidad magrebí. Traducción del francés de Juan Vivanco. Barcelona: Edicions Bellaterra, 1997.

El Feki, Shereen. Sex and the citadel: intimate life in a changing Arab world. Londres: Vintage Books, 2013.

El Tahawi, Mouna. "Sex talk for muslim women". The New York times. https://www. nytimes.com/2016/05/06/opinion/sex-talk-for-muslim-women.html?_r=0. 26 diciembre 2017.

Ghribi, Asma. "Don't fall for Tunisian president's fake Feminism" The Washington Post, 2017. https://www.washingtonpost.com/news/democracy-post/wp/2017/10/03/ dont-fall-for-the-tunisian-presidents-fake-feminism/?utm_term=.a9cd88e23314. 10 enero 2018.

González, Ricard. "Prostitución, la otra excepción tunecina". El País, 2016. http:// elpais.com/elpais/2016/01/11/eps/1452526145_812741.html. 23 diciembre 2017.

—. "Shams Rad, la primera radio gay del mundo árabe". El País, 2018. https://elpais. com/elpais/2018/01/07/opinion/1515339334_495579.amp.html?__twitter_ impression=true. 9 enero 2018.

Feminismo/s 31, junio 2018, pp. 83-106 
Haddad, Joumana. Yo mate a Sherezade. Confesiones de una mujer árabe furiosa. Traducción de Marta Mabres Vicens. Barcelona: Penguin Random House, 2011. Izquierdo, Ferrán. Poder y regímenes en el mundo árabe contemporáneo. Barcelona: Edicions Bellaterra, 2009.

Lapiedra, Eva. "Espacios y tiempos de intimidad. La mujer en el ámbito de lo inexpugnable y lo sagrado". Paisajes, espacios y objetos de devoción en el Islam. Eds. Fátima Roldán y Alejandra Contreras. Sevilla: Editorial Universidad de Sevilla, 2017. 91-116.

Marín, Manuela. "Coran XXIV,60 y XXXIII: sobre el tabarruŷ de las mujeres" Eds. Miguel H. de Larramendia y Salvador Peña. El Corán ayer y hoy: Perspectivas actuales sobre el islam, estudios en honor del profesor Julio Cortés. Córdoba: Berenice, 2008. 215-231.

OIM Tunisie. Étude exploratoire sur la traite des personnes en Tunisie. Túnez, 2013.

Rodríguez, Lilia. "Derechos sexuales y reproductivos en el marco de los derechos humanos". Decidiresunderecho.org http://www.decidiresunderecho.org/index.php/ publicaciones/file/derechos-sexuales-y-reproductivos-en-el-marco-de-los-derechos-humanos?id=6. 14 abril 2018.

Ruiz Almodóvar, Carmen. "El Código Tunecino de Estatuto Personal". MEAH: Miscelánea de Estudios Árabes y Hebraicos 44, 40 (1995). Universidad de Granada. Sánchez Mediavilla, Emilio. "Joumana Haddad, la estirpe de Lilit" Altair Magazine. https://www.altairmagazine.com/voces/joumana. 26 diciembre 2017.

Sbouai, Sana. "Article 230 du code pénal: la criminalisation anticonstitutionnelle" Inkyfada, 2015. https://inkyfada.com/2015/05/article-230-code-penal-criminalisation-anticonstitutionnelle-homosexualite-tunisie/. 30 diciembre 2017.

—. "Esclave en Tunisie". Inkyfada. 2015. https://inkyfada.com/2015/08/domestique-etrangere-bonne-esclave-tunisie/. 10 abril 2018.

Semerene, Gabriel. "The words to say it". Mashakkah News. https://www.mashallahnews.com/language/words-to-say.html. 30 diciembre 2017.

Shams. Au pays de la démocratie naissante. Túnez, 2017.

Youssef, Olfa. "Fī-l-mas'ala al-ŷinsīya fī-l-islām". YouTube 2016. https://www.youtube. $\mathrm{com} /$ watch?v=FtC9U3ppbQU\&t=101s. 28 octubre 2017.

—. "Al-mitliyat al-ŷinsiya maskut 'anha fī-l-islām". YouTube, 2016. https://www.youtube.com/watch?v=k33dufSUjHO. 26 diciembre 2017. 